\title{
Erratum to: Readthrough of nonsense mutations in Rett syndrome: evaluation of novel aminoglycosides and generation of a new mouse model
}

\author{
Cornelia Brendel • Valery Belakhov • Hauke Werner • \\ Eike Wegener • Jutta Gärtner • Igor Nudelman • \\ Timor Baasov • Peter Huppke \\ Published online: 16 April 2013 \\ (C) Springer-Verlag Berlin Heidelberg 2013 \\ Erratum to: J Mol Med (Berl) 2011; 89:389-398 \\ DOI 10.1007/s00109-010-0704-4
}

It has been brought to our attention that the two blots showing the loading controls in Fig. 1a and 1b look identical (p. 390). The authors deeply regret this error which was due to careless data management. They apologize for this oversight and have prepared a corrected version of Fig. 1a which is given below. The major findings and conclusions of this paper are not affected by these changes.

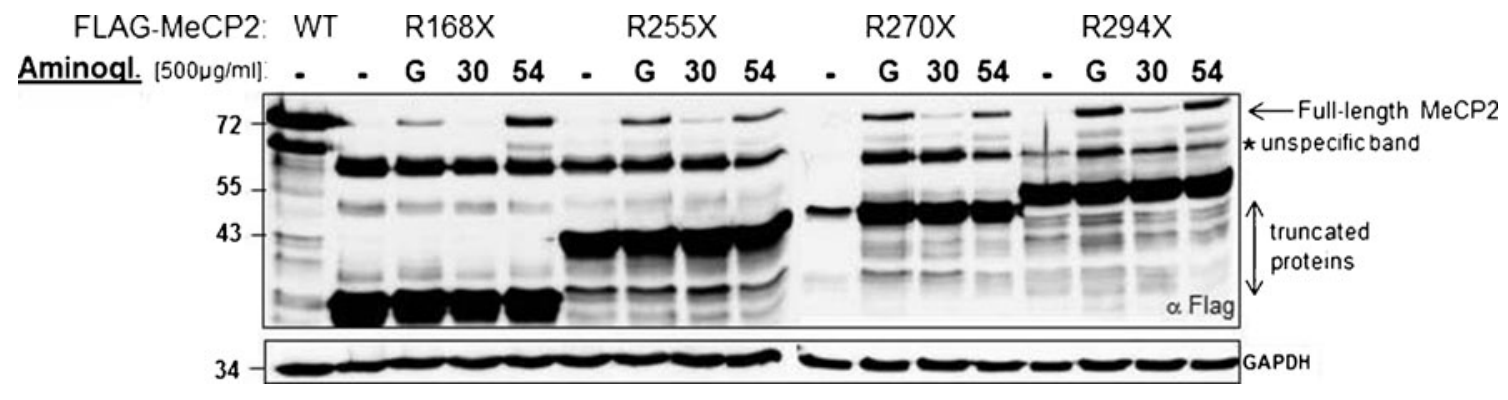

The online version of the original article can be found at http://dx.doi.org/ 10.1007/s00109-010-0704-4.

C. Brendel · E. Wegener · J. Gärtner · P. Huppke

Department of Pediatrics and Pediatric Neurology,

Georg August University,

Goettingen, Germany

\section{Belakhov $\cdot$ I. Nudelman · T. Baasov}

The Edith and Joseph Fischer Enzyme Inhibitors Laboratory,

Schulich Faculty of Chemistry,

Technion-Israel Institute of Technology,

Haifa 32000, Israel
H. Werner

Department of Neurogenetics,

Max Planck Institute of Experimental Medicine,

Goettingen, Germany

\section{P. Huppke $(\bowtie)$}

Department of Pediatrics and Pediatric Neurology,

University Medical Center Göttingen, Georg August University,

Robert-Koch-Strasse 40, 37075 Göttingen, Germany

e-mail: phuppke@med.uni-goettingen.de 